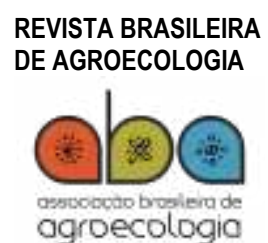

ISSN: 1980-9735

DOI: 10.33240/rba.v14i3.22799

Vol. 14 | №. 3 | p. $40-53$ | 2019

\title{
ESPÉCIES VEGETAIS USADAS COMO REPELENTES E INSETICIDAS NO ESTADO DO AMAPÁ, BR
}

\author{
Plant species used as repellents and insecticides in the state of Amapá, BR
}

1 Doutor, Núcleo de Biodiversidade, Instituto de Pesquisas Científicas e Tecnológicas do Estado do Amapá, Macapá, Brasil.

E-mail: raullyanborja@gmail.com

2 Doutor, Departamento de Ciências Biológicas e da Saúde, Universidade Federal do Amapá, Macapá, Brasil

E-mail: fernandomedeiros@unifap.br

${ }^{3}$ Doutor, Departamento de Ciências Biológicas e da Saúde, Universidade Federal do Amapá, Macapá, Brasil E-mail: rnpsouto50@gmail.com

\section{Recebido em:}

05/08/2018

Aceito para publicação em: $28 / 06 / 2019$

Correspondência para: raullyanborja@gmail.com

\author{
Raullyan Borja Lima e Silva ', Fernando Antônio de Medeiros ${ }^{2}$ \\ e Raimundo Nonato Picanço Souto ${ }^{3}$
}

RESUMO

Ao longo da história humana, alguns insetos, têm sido responsáveis pelos danos causados em suas culturas e por apresentar relevante importância médica, pois são vetores de várias doenças, como são os mosquitos. Estratégias têm sido usadas no seu controle, com destaque para os inseticidas sintéticos, que não são seguros e sua eficiência é temporária, além de possuírem alto custo de produção. Portanto, é importante a busca por produtos naturais que tenham a potencialidade efetiva de controle aos mosquitos. Esta pesquisa objetivou realizar o levantamento do estado da arte etnobotânico e etnofarmacológico de espécies vegetais usadas como repelentes e/ou inseticidas no estado Amapá. A coleta de dados foi realizada a partir de publicação científica-acadêmica. Foram catalogadas 25 espécies distribuídas em 19 famílias e 21 gêneros. A família que se destacou pelo número de espécies foi Piperaceae. Os gêneros com maior abundância de espécies foram: Piper, Attalea e Justicia. Fica evidente a riqueza da diversidade vegetal potencial para estudos fitoquímicos e promissoras substâncias bioativas na região do Amapá.

Palavras-chave: Conhecimento tradicional. Etnoconhecimento. Etnobotânica.

\section{ABSTRACT}

Throughout human history, insects have been responsible for the damage caused in their cultures and for having relevant medical importance, as they are vectors of various diseases, as mosquitoes are. Strategies have been used to control these animals, especially by synthetic insecticides, which are not safe, efficient, and also are expensive. Therefore, it is important to search for natural products that have the effective potential to control mosquitoes. The objective of this research was to survey ethnobotanical and ethnopharmacological plant species used as repellent and/or insecticide in Amapá state. Data were collected from scientific-academic publication. A total of 25 plant species were cataloged in 19 families and 21 genera. The family with the highest number of species was Piperaceae. The most important genera by the number of species were: Piper, Attalea, and Justicia. It is evident the richness of potential plant diversity for phytochemical studies and promising discoveries of new bioactive substances in the region.

Keywords: Traditional knowledge. Ethnoconference. Ethnobotany. 
Introdução

O homem desde seus primórdios tem acompanhado no convívio com insetos que ora os ajuda, como são as abelhas e ora os restringem na saúde, como são os insetos, vetores de várias enfermidades como a dengue, chikungunya, zika, febre amarela e malária, têm sido de interesse para saúde pública em vários países causado numerosos casos em todo o planeta, inclusive com registro de óbitos (CONSOLI, 1994; VASCONCELOS, 2015; SOUZA, 2016).

As ações mais difundidas e utilizadas para o controle dos mosquitos, nos programas de controle de vetores utilizam inseticidas sintéticos, principalmente os inseticidas organofosforados. Contudo, esses apresentam baixa seletividade, danos ecológicos e a seleção de populações de insetos resistentes (BRAGA e VALE, 2007; CRIVELENTI et al., 2011; GARCEZ et al., 2013).

Em vários países e em diversos estados do Brasil, já foram identificados mosquitos resistentes a inseticidas, fato que agrava ainda mais o número de aplicações do produto, elevando os custos para o controle dos insetos (REY et al., 2010; HORTA et al., 2011).

Em contrapartida, há uma grande procura por substâncias naturais com ação ou potencial inseticida e/ou repelente, pois representam uma melhor opção tanto com relação a gastos, eficiência e por serem mais biodegradáveis que os inseticidas sintéticos (CASTRO, 2007).

Viegas Junior (2003) e Barreto (2005) apontam que biosubstâncias são menos prejudiciais para a saúde humana e para o meio ambiente, tendo como alternativa a utilização de extratos de plantas baseando-se no método de utilização de compostos químicos (aleloquímicos) produzidos pelo metabolismo secundário de algumas espécies vegetais com a finalidade de protegê-las do ataque de insetos herbívoros (VIEGAS JUNIOR, 2003; BARRETO, 2005). Esses metabólitos secundários como os flavonoides, alcaloides e terpenóides que coevoluem com os insetos e microrganismos, tornam-se fontes naturais de substâncias inseticidas (SIMÕES et al., 2010; MARANGONI et al., 2012). Segundo Castro et al. (2010), os produtos naturais extraídos de plantas são fontes promissoras contra insetos. Os flavonoides são substâncias presentes em diversos vegetais, conferindo às flores, aos frutos e outras partes da planta, colorações diversificadas (SANTOS et al., 2012). Ademais, apresentam atividade sobre a permeabilidade capilar, antioxidante, anti-inflamatória, antiviral, antitumoral e hormonal. Os alcaloides, por sua vez são bases orgânicas nitrogenadas que regulam o crescimento do vegetal e atuam na defesa química das plantas contra predadores, devido ao seu potencial citotóxico (ALVES e SILVA, 2002; SANTOS et al., 2012). Os terpenóides são os compostos responsáveis pelo aroma das plantas e apresentam funções variadas nos vegetais, tais como de proteção contra fungos, bactérias e herbívoros (HOLETZ et al., 2002; MORITA et al., 2000).

Pesquisas são crescentes na identificação de espécies vegetais potenciais para a obtenção de inseticidas naturais menos poluentes e mais seletivos para o controle populacional de vetores (GUISSONI et al., 2013). Segundo Aciole (2009) e Farias A. (2012), os extratos e óleos essenciais de plantas de ação inseticida estão sendo cada vez mais estudados e testados a fim de poderem encontrar novas substâncias que tenham ação sobre as pragas e para que as mesmas diminuam a dependência dos inseticidas químicos. Dessa forma, a busca por inseticidas de origem botânica que atuem no controle populacional de mosquitos é essencial (TAVIL, 2010; AZEVEDO et al., 2011; GARCIA, 2014).

A utilização de plantas e dos seus derivados, pelo homem, com propriedades inseticidas é uma prática muito antiga (ROEL, 2001; GALLO et al., 2002), a qual foi quase abandonada com o advento dos produtos organo-sintéticos, mas estes foram usados de forma abusiva e, com isso, foram gerados vários problemas ambientais, sociais e de saúde pública. Extratos de plantas inseticidas ressurgem como objeto de pesquisa e vêm sendo estudados como alternativa aos agrotóxicos no manejo integrado de pragas (ROEL et al., 2000). Outra vantagem dos defensivos naturais é que algumas moléculas apresentam estrutura química bastante complexa, o que torna mais difícil os insetos-alvo desenvolverem resistência sobre elas. Com isto, os inseticidas provenientes de uma grande diversidade de espécies vegetais apresentam grande potencial de uso no futuro, reduzindo, assim o uso abusivo dos inseticidas sintéticos e consequentemente dos danos ambientais (MORAIS e MARINHO-PRADO, 2016). 
Morais (2011) coloca que há a necessidade de se incentivar o resgate do conhecimento tradicional de práticas existentes antes do advento dos defensivos sintéticos.

No estado do Amapá, comunidades tradicionais detém um grande conhecimento das mais variadas espécies vegetais com ação inseticida e/ou repelente, para o controle de vetores de doenças, e no controle de pragas agrícolas. Dessa forma, a investigação objetivou realizar o levantamento do estado da arte etnobotânico e etnofarmacológico de espécies vegetais usadas como repelente e/ou inseticida no estado do Amapá, visando oferecer suporte para pesquisas aplicadas, que terá como finalidade contribuir para fins práticos, mais ou menos imediatos, buscando soluções para problemas concretos, como sanar ou amenizar problemas de doenças vetorizadas por insetos.

\section{Metodologia}

Foi realizada busca ampla de produção científica que versassem sobre o potencial etnobotânico do estado do Amapá. A referida investigação possui caráter descritivo e sugere o uso do método quanti-qualitativo de multi-casos, visando uma maior compreensão dos dados coletados. A base dessa investigação foi a pesquisa bibliográfica, em documentos, buscando conhecer e analisar as contribuições culturais e/ou científicas sobre o tema proposto, ou seja, o estado da arte atual da etnobotânica e da Etnofarmacologia no estado do Amapá.

\section{Técnicas e instrumentos de pesquisa}

Procedimentos: a) Levantamento do estado da arte dos trabalhos realizados sobre espécies vegetais citadas, coletadas e identificadas no estado do Amapá, usadas como repelentes e/ou inseticidas, com o intuito de criar um banco de dados; b) Identificação, seleção e registro das espécies vegetais citadas nos trabalhos usadas como repelentes e/ou inseticidas e suas formas de uso.

Pesquisa bibliográfica foi realizada em: Instituições de Pesquisa e Ensino Superior no Amapá; Boletins científicos; Revistas; Livros; Periódicos científicos (Impressos e Digitais) e trabalhos acadêmicos. Para tanto foram consultadas obras especializadas, os bancos taxonômicos virtuais, que reúnem bibliografias e informações sobre as espécies citadas.

Em atendimento à Lei no 13.123/2015, o trabalho foi cadastrado no Sistema Nacional de Gestão do Patrimônio Genético e do Conhecimento Tradicional Associado (SISGEN), sob o no ACFE659.

Foi organizado banco de dados com as informações de todas as espécies registradas com breve descrição geral, ecológica, etnofarmacológica e etnobotânica. Como critérios de inclusão das espécies no banco de dados, as mesmas deveriam constar, na obra de referência, uma descrição que pudesse identificar a planta de forma científica, utilização prática como repelente e/ou inseticida, parte usada e forma de uso.

Como instrumento de coleta e registro dos dados, utilizou-se um formulário com espaços para anotação das informações referentes aos trabalhos publicados, assim como foi utilizado um scanner portátil para fazer o registro digital das informações de forma prática, diretos e seguros, sendo, depois, transportados para o banco de dados.

\section{Organização e análise dos dados}

Os dados coletados foram registrados em cadernetas específicas para este fim, organizados e sistematizados em fichas por trabalho individualmente, tabulados e sintetizados através do programa Microsoft Office Excel 2013 para a formação de um banco de dados. Os dados foram analisados qualitativamente, visando obter a descrição do conteúdo sistemático e objetivo, permitindo a 
inferência de conhecimentos relativos às condições de produção/recepção das mensagens. Na busca para atingir o significado manifesto, utilizou-se a análise temática proposta por Minayo (2014).

A composição florística foi avaliada pela riqueza dos indivíduos distribuídos em gêneros e espécies. Os nomes das famílias foram atualizados utilizando a classificação adotada pelo Angiosperm Phylogene Group IV (APG IV, 2016). A revisão da nomenclatura taxonômica foi de acordo com Lista de Espécies da Flora do Brasil (FORZZA et al., 2018), Tropicos - Missouri Botanical Garden (TROPICOS.ORG, 2018) e The Plant List (THE PLANT LIST, 2013), pois, como colocado por McNeil et al. (2007), muitas espécies têm seus nomes modificados ao longo do tempo. Neste sentido, mudanças nos nomes de espécies, de gêneros, famílias, sinonimizações, mudanças de ortografia e abreviações corretas dos autores das espécies, foram detectadas e atualizadas.

\section{Resultados e discussão}

No inventário dos trabalhos pesquisados foram registradas como válidas, 25 espécies incluídas em 19 famílias e 21 gêneros. Na Tabela 1, as espécies são apresentadas por sua nomenclatura vernacular (etnoespécie), nome científico, família e indicação de uso popular.

Tabela 1. Relação das espécies registradas no inventário, com indicação de uso repelente (R) e/ou inseticida (I), (2015).

\begin{tabular}{|c|c|c|c|}
\hline Etnoespécie & Nome Científico & Família & Indicação de uso \\
\hline Açaizeiro & Euterpe oleracea Mart. & Arecaceae & $\mathrm{R}$ \\
\hline Anajazeiro, inajazeiro, anajá, inajá & Attalea maripa (Aubl.) Mart. & Arecaceae & $\mathrm{R}$ \\
\hline Andirobeira, andiroba, janyro & Carapa guianensis Aubl. & Meliaceae & $\mathrm{R}$ \\
\hline Anuerá, anoerá, anauerá & Licania macrophylla Benth. & Chrysobalanaceae & 1 \\
\hline Arruda & Ruta graveolens L. & Rutaceae & $\mathrm{R} / \mathrm{I}$ \\
\hline Ata & Annona squamosa $\mathrm{L}$. & Annonaceae & $\mathrm{R} / \mathrm{I}$ \\
\hline Babosa & Aloe vera (L.) Burm. f. & Xanthorrhoeaceae & $\mathrm{R}$ \\
\hline $\begin{array}{l}\text { Capim Santo, erva cidreira, capim } \\
\text { cheiroso, capim marinho, capim } \\
\text { limão }\end{array}$ & Cymbopogon citratus (DC.) Stapf & Poaceae & $\mathrm{R}$ \\
\hline $\begin{array}{l}\text { Castanha do Brasil, castanha do } \\
\text { Pará, castanheira }\end{array}$ & Bertholletia excelsa Bonpl. & Lecythidaceae & $\mathrm{R} / \mathrm{I}$ \\
\hline $\begin{array}{l}\text { Catinga de mulata, cheiro de } \\
\text { mulata }\end{array}$ & Aeollanthus suaveolens Mart. ex Spreng. & Lamiaceae & $R / I$ \\
\hline Cebola & Allium cepa $\mathrm{L}$. & Amaryllidaceae & $\mathrm{R}$ \\
\hline Cedro & Cedrela fissilis Vell. & Meliaceae & $\mathrm{R}$ \\
\hline Cipó de Alho & Mansoa alliacea (Lam.) A.H. Gentry & Bignoniaceae & $\mathrm{R}$ \\
\hline Copaibeira, copaíba & Copaifera sp. & Fabaceae & $\mathrm{R}$ \\
\hline Elixir paregórico, óleo elétrico & Piper callosum Ruiz \& Pav. & Piperaceae & 1 \\
\hline Eucalipto roxo, eucalipto pequeno & Justicia sp. 1 & Acanthaceae & $\mathrm{R} / \mathrm{I}$ \\
\hline Forsangue & Justicia sp. 2 & Acanthaceae & $\mathrm{R} / \mathrm{I}$ \\
\hline $\begin{array}{l}\text { Mastruz, mastruço, erva de santa } \\
\text { maria }\end{array}$ & $\begin{array}{l}\text { Dysphania ambrosioides (L.) Mosyakin \& } \\
\text { Clemants }\end{array}$ & Amaranthaceae & 1 \\
\hline Mucuracaá & Petiveria alliacea $\mathrm{L}$. & Phytolaccaceae & $\mathrm{R}$ \\
\hline Pau de ângola & Piper divaricatum G. Mey. & Piperaceae & $\mathrm{R} / \mathrm{I}$ \\
\hline Pau mulateiro, pau mulato & $\begin{array}{l}\text { Calycophyllum spruceanum (Benth.) } \\
\text { Hook.f. ex K.Schum. }\end{array}$ & Rubiaceae & $\mathrm{R} / \mathrm{I}$ \\
\hline Pimenta de macaco & Piper aduncum L. & Piperaceae & $\mathrm{R} / \mathrm{I}$ \\
\hline Salva de marajó, sarva & Hyptis crenata Pohl ex Benth. & Lamiaceae & $\mathrm{R}$ \\
\hline Tabaco & Nicotiana tabacum L. & Solanaceae & $\mathrm{R}$ \\
\hline Urucurizeiro, urucuri & Attalea phalerata Mart. ex Spreng. & Arecaceae & $\mathrm{R}$ \\
\hline
\end{tabular}


Das espécies catalogadas, 13 (52\%) são exclusivamente usadas como repelente, 3 (12\%) como inseticidas e 9 (36\%) para ambos os usos.

\section{Famílias botânicas das espécies vegetais identificadas como repelentes e/ou inseticidas}

As famílias botânicas que tiverem maior riqueza de espécies na indicação de uso como repelente e/ou inseticida foram: Piperaceae ( $n=3$ espécies=12\%), Acanthaceae, Arecaceae, Lamiaceae e Meliaceae ( $n=2$ espécies, cada=8\%). As demais famílias foram registradas com uma única espécie $(n=1=4 \%)$ (Tabela 21).

Tabela 2. Famílias botânicas catalogadas usadas como repelente e/ou inseticida (2015).

\begin{tabular}{|c|c|c|}
\hline Família & $\begin{array}{l}\text { Frequência Absoluta - № } \\
\text { Espécies Catalogadas }\end{array}$ & $\begin{array}{c}\text { Frequência Relativa } \\
(\%)\end{array}$ \\
\hline Piperaceae & 3 & 12 \\
\hline Acanthaceae, Arecaceae, Lamiaceae, Meliaceae & $2($ cada $)=8$ & $8($ cada $)=32$ \\
\hline $\begin{array}{l}\text { Arecaceae, Amaranthaceae, Amaryllidaceae, Annonaceae, } \\
\text { Bignoniaceae, Chrysobalanaceae, Fabaceae, Lecythidaceae, } \\
\text { Phytolaccaceae, Poaceae, Rubiaceae, Rutaceae, Solanaceae, } \\
\text { Xanthorrhoeaceae }\end{array}$ & 1 (cada) $=14$ & $4($ cada $)=56$ \\
\hline Total & 25 & 100,00 \\
\hline
\end{tabular}

A família Piperaceae engloba cerca de 2500 espécies, as quais são distribuídas em cinco gêneros com distribuição, predominantemente, tropical (KATO e FURLAN, 2007). No Brasil, compreende quatro gêneros e cerca de 500 espécies (YUNCKER, 1972, 1973, 1974).

As Piperaceae possuem óleos essenciais, mono e sesquiterpenos, pironas, polifenóis, ligninas e alcaloides (SCHULTES e RAFFAUF, 1990) e várias espécies são cultivadas como ornamentais ou utilizadas na alimentação e na medicina caseira (PESSINI et al., 2003; GUIMARÃES e MONTEIRO, 2006), bem como nas indústrias farmacêuticas de cosméticos e de inseticidas (SILVA e MACHADO, 1999).

As Piperaceae são fontes promissoras como inseticidas, pelo fato de terem menores efeitos sobre mamíferos e um grande número de metabólitos secundários e óleos essenciais (NASCIMENTO e POTIGUARA, 1999). Farias et al. (2016) encontraram como famílias mais mencionadas Meliaceae, Lamiaceae e Poaceae, enquanto Roel (2001) destacou Solanaceae, Chenopodiaceae e Liliaceae como as principais famílias botânicas com potencial bioinseticida, corroborando com a relação das espécies neste artigo.

\section{Gêneros botânicos das espécies vegetais identificadas como repelentes e/ou inseticidas}

Os gêneros que apresentaram maior número de espécies indicadas como repelente e/ou inseticida foram: Piper (12\%), Attalea e Justicia (espécies=8\%). Os demais gêneros foram registrados com uma única espécie (4\%) (Tabela 3).

Tabela 3. Gêneros botânicos catalogados usados como repelente e/ou inseticida (2015).

\begin{tabular}{|c|c|c|}
\hline Gênero & $\begin{array}{c}\text { Frequência Absoluta } \\
\text { № Espécies Catalogadas }\end{array}$ & $\begin{array}{c}\text { Frequência Relativa } \\
\text { (\%) }\end{array}$ \\
\hline Piper & 3 & 12 \\
\hline Attalea & 2 & 8 \\
\hline Justicia & 2 & 8 \\
\hline $\begin{array}{l}\text { Aeollanthus, Allium, Aloe, Annona, } \\
\text { Bertholletia, Calycophyllum, Carapa, Cedrela, } \\
\text { Copaifera, Cymbopogon, Dysphania, Euterpe, } \\
\text { Hyptis, Licania, Mansoa, Nicotiana, Petiveria, } \\
\text { Ruta, }\end{array}$ & 1 (cada) $=18$ & $4($ cada $)=72$ \\
\hline Total & 25 & 100,00 \\
\hline
\end{tabular}


O gênero Piper é um arbusto encontrado em regiões tropicais e subtropicais conhecido por seu alto poder medicinal (GONÇALVES e LIMA, 2016) e agricultores usam como pesticidas contra pragas (BEZERRA et al., 2007). Lago et al. (2004) apontam que o interesse na identificação de novos compostos em espécies do gênero Piper se intensificou devido à detecção de diversas substâncias biologicamente ativas, pois este gênero caracteriza-se pela produção de classes típicas de compostos diversos, como amidas, ácidos benzoicos lignanas e alcaloides. Estrela et al. (2003) afirmam que a piperina foi a primeira amida a ser isolada de espécies de Piper e que tem maior atividade inseticida do que as piretrinas, as quais, segundo Soderlund et al. (2002) são substâncias amplamente comercializadas no planeta. Estrela et al. (2006) afirmam que espécies de Piper, em especial a Piper aduncum L., possuem potencial de uso para o manejo e controle de insetos de importância econômica e médica.

Aspectos etnobotânicos e etnofarmacológicos das espécies catalogadas como repelentes e/ou inseticidas

$\mathrm{Na}$ Tabela 4, as espécies são apresentadas em pranchas individuais com as seguintes informações: Nome vernacular (etnoespécie); nome científico; família; hábito de crescimento no ambiente; local da informação, principais obras de referência à espécie; e informações etnobotânicas e etnofarmacológicas referentes à potencialidade repelente e/ou inseticida, bem como de outros usos medicinais.

\section{Partes usadas e formas de vida das espécies usadas como repelentes e/ou inseticidas}

Várias partes das plantas nas espécies vegetais registradas são usados nas preparações com finalidade de repelência e/ou inseticida, folhas $(35,48 \%)$, planta inteira $(22,58 \%)$, caules $(16,13 \%)$ e sementes $(12,90 \%)$. Brácteas, bulbos, cachos e flores (3,23\% cada) também são utilizados. Farias et al. (2016) registrou em uma comunidade rural no nordeste brasileiro como partes de plantas mais usadas como repelentes e inseticidas, planta inteira $(51,30 \%)$, as folhas $(35 \%)$ e casca do fruto $(7 \%)$ e casca do caule $(4,10)$. Kweka et al. (2008) apontam que, na região nordeste da Tanzânia, as comunidades utilizam mais comumente as folhas (70\%), a planta inteira (13\%), as cascas $(10 \%)$ e raízes (7\%). Araújo et al. (2018) apontam que, em levantamento de plantas fitossanitárias usadas para evitar perdas na produção agrícola, a parte vegetal mais utilizada no preparo dos extratos que atuam como repelente e/ou inseticida são as folhas (62,96\%). Villavicencio-Nieto et al. (2010) realizaram estudo sobre o uso de plantas como praguicidas no estado de Hidalgo, no México e catalogaram ramos $(49,19 \%)$, folhas $(23,39 \%)$ e planta inteira $(9,68 \%)$, como os órgãos vegetais mais usados. 
Tabela 4. Relação das espécies catalogadas no inventário usadas como repelente e/ou inseticida no Amapá.

\begin{tabular}{|c|c|c|c|c|c|c|c|}
\hline Etnoespécie & Nome Científico & Família & Forma de Vida & Local da Informação & $\begin{array}{l}\text { Principais obras de } \\
\text { referência }\end{array}$ & Parte usada & Modo de Uso \\
\hline Açaizeiro, açaí & Euterpe oleracea Mart. & Arecaceae & Arbóreo & $\begin{array}{l}\text { Carvão, Curiaú, } \\
\text { Mazagão Velho, } \\
\text { Floresta Nacional do } \\
\text { Amapá (Flona) }\end{array}$ & $\begin{array}{l}\text { Silva (2002, 2010), } \\
\text { Nascimento (2011), } \\
\text { Farias J (2012), } \\
\text { Costa R. (2013) }\end{array}$ & - Cacho & $\begin{array}{l}\text { - Queimar os cachos para } \\
\text { produzir fumaça que afasta } \\
\text { os insetos }\end{array}$ \\
\hline $\begin{array}{l}\text { Anajazeiro, } \\
\text { inajazeiro, anajá, } \\
\text { inajá }\end{array}$ & Attalea maripa (Aubl.) Mart. & Arecaceae & Arbóreo & Flona & Costa R. (2013) & - Folhas & $\begin{array}{l}\text { - Queimar as folhas para a } \\
\text { fumaça espantar os insetos }\end{array}$ \\
\hline $\begin{array}{l}\text { Andirobeira, } \\
\text { andiroba, janyro }\end{array}$ & Carapa guianensis Aubl. & Meliaceae & Arbóreo & $\begin{array}{l}\text { Carvão, Curiaú, } \\
\text { Mazagão Velho, } \\
\text { Ajuruxi, Maracá, } \\
\text { Wajãpi, Mazagão- } \\
\text { estuário, Flona }\end{array}$ & $\begin{array}{l}\text { Silva (2002, 2010), } \\
\text { Nascimento (2011), } \\
\text { Silva et al. (2013), } \\
\text { Xavier e Cunha } \\
\text { (2015), Mata } \\
\text { (2009), Farias J. } \\
\text { (2012), Santos et al. } \\
\text { (2014), Santos } \\
\text { (2006), Costa E. } \\
\text { (2013) }\end{array}$ & $\begin{array}{l}\text { - Óleo das } \\
\text { sementes } \\
\text { (azeite de } \\
\text { andiroba); } \\
\text { - Folhas } \\
\text { - Cascas das } \\
\text { sementes }\end{array}$ & $\begin{array}{l}\text { - Passar o óleo no corpo } \\
\text { misturado com urucum } \\
\text { para repelir os insetos; } \\
\text { - Queimar as folhas para } \\
\text { afugentar os insetos; } \\
\text { - Queimar as cascas de } \\
\text { sementes para afugentar os } \\
\text { insetos }\end{array}$ \\
\hline $\begin{array}{l}\text { Anuerazeiro, } \\
\text { anuerá, anoerá, } \\
\text { anauerá }\end{array}$ & Licania macrophylla Benth. & Chrysobalanaceae & Arbóreo & $\begin{array}{l}\text { Mazagão Velho, } \\
\text { Ajuruxi, Maracá, APA } \\
\text { da Fazendinha, } \\
\text { Mazagão-estuário, } \\
\text { Flona }\end{array}$ & $\begin{array}{l}\text { Nascimento (2011), } \\
\text { Ramos et al. (2015), } \\
\text { Farias J (2012), } \\
\text { Costa R. (2013) }\end{array}$ & $\begin{array}{l}\text { - Cascas do } \\
\text { caule }\end{array}$ & $\begin{array}{l}\text { - Fazer o chá e passar no } \\
\text { corpo; } \\
\text { - Fazer o macerado do } \\
\text { material e passar no corpo }\end{array}$ \\
\hline Arruda & Ruta graveolens L. & Rutaceae & Sub-arbustivo & $\begin{array}{l}\text { Carvão, Curiaú, } \\
\text { Mazagão Velho, } \\
\text { Mazagão-estuário, } \\
\text { Flona }\end{array}$ & $\begin{array}{l}\text { Silva (2002, 2010), } \\
\text { Nascimento (2011), } \\
\text { Silva et al. (2013), } \\
\text { Xavier e Cunha } \\
\text { (2015), Farias J. } \\
\text { (2012), Costa, R. } \\
\text { (2013) }\end{array}$ & - Folhas & $\begin{array}{l}\text { - O chá forte jogado nas } \\
\text { locais por onde passam os } \\
\text { insetos; } \\
\text { - Tintura passar no local; } \\
\text { - Banhar o corpo com o chá } \\
\text { forte }\end{array}$ \\
\hline Ata & Annona squamosa $\mathrm{L}$. & Annonaceae & Arbóreo & Carvão (Mazagão) & Silva (2010) & - Sementes & $\begin{array}{l}\text { - As sementes devem ser } \\
\text { trituradas até ficar um pó } \\
\text { que deve ser queimada e } \\
\text { servem para espantar } \\
\text { insetos; } \\
\text { - Pó passado no corpo serve } \\
\text { de repelente a insetos }\end{array}$ \\
\hline Babosa & Aloe vera (L.) Burm. $\mathrm{f}$. & Xanthorrhoeaceae & Herbáceo & Carvão, Curiaú, Flona & $\begin{array}{l}\text { Silva }(2002,2010), \\
\text { Costa R. }(2013)\end{array}$ & - Folhas & $\begin{array}{l}\text { - Sumo passar no corpo } \\
\text { para repelir insetos }\end{array}$ \\
\hline $\begin{array}{l}\text { Capim santo, erva } \\
\text { cidreira, capim } \\
\text { cheiroso, capim } \\
\text { marinho, capim } \\
\end{array}$ & $\begin{array}{l}\text { Cymbopogon citratus (DC.) } \\
\text { Stapf }\end{array}$ & Poaceae & Herbáceo & Carvão, Curiaú, Flona & $\begin{array}{l}\text { Silva (2002, 2010), } \\
\text { Silva et al. (2013), } \\
\text { Costa R. (2013) }\end{array}$ & $\begin{array}{l}-\quad \text { Planta } \\
\text { inteira; } \\
-\quad \text { Folhas + } \\
\end{array}$ & $\begin{array}{l}\text {-Queimar a planta seca para } \\
\text { a fumaça espantar insetos; } \\
\text {-Colocar várias folhas e } \\
\text { flores em um saco de pano }\end{array}$ \\
\hline
\end{tabular}




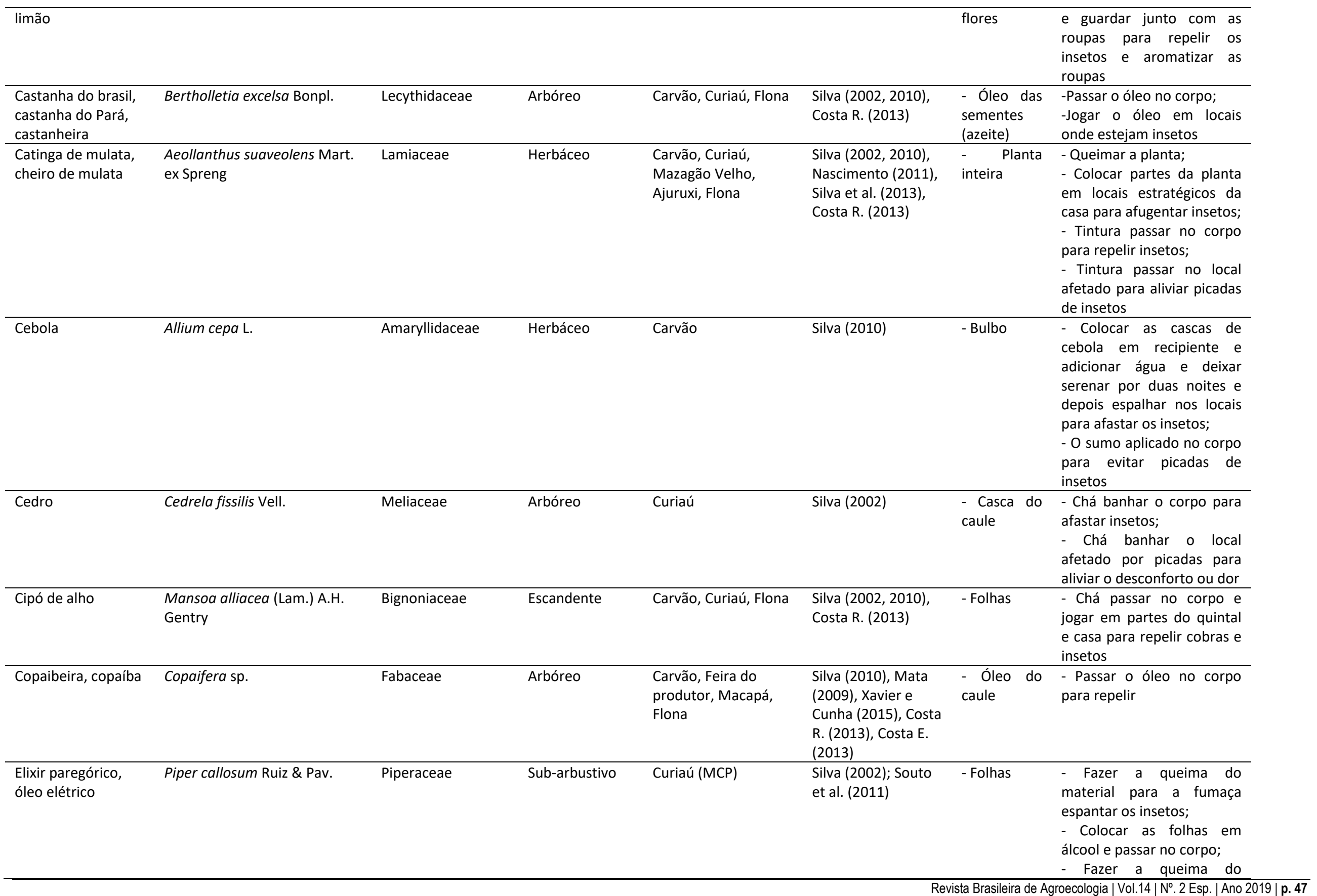




\begin{tabular}{|c|c|c|c|c|c|c|c|}
\hline & & & & & & - Caule & $\begin{array}{l}\text { material para a fumaça } \\
\text { espantar os insetos }\end{array}$ \\
\hline Eucalipto roxo & Justicia sp. & Acanthaceae & Arbustivo & Carvão, Curiaú, Flona & $\begin{array}{l}\text { Silva }(2002,2010), \\
\text { Costa R. }(2013), \\
\text { Rodrigues (2008) }\end{array}$ & $\begin{array}{l}\text { - Planta } \\
\text { inteira }\end{array}$ & $\begin{array}{l}\text { - Queimar o material para } \\
\text { espalhar a fumaça e } \\
\text { espantar os insetos }\end{array}$ \\
\hline Forsangue & Justicia sp.2 & Acanthaceae & Arbustivo & Carvão & Silva (2010) & $\begin{array}{l}\text { - Planta } \\
\text { inteira }\end{array}$ & $\begin{array}{l}\text { - Queimar o material para } \\
\text { espalhar a fumaça e } \\
\text { espantar os insetos }\end{array}$ \\
\hline $\begin{array}{l}\text { Mastruz, mastruço, } \\
\text { erva de santa maria }\end{array}$ & $\begin{array}{l}\text { Dysphania ambrosioides (L.) } \\
\text { Mosyakin \& Clemants }\end{array}$ & Amaranthaceae & Herbáceo & $\begin{array}{l}\text { Carvão, Curiaú, } \\
\text { Mazagão Velho, } \\
\text { Maracá, Ajuruxi, } \\
\text { Mazagão-estuário, } \\
\text { Flona }\end{array}$ & $\begin{array}{l}\text { Silva (2002, 2010), } \\
\text { Nascimento (2011), } \\
\text { Silva et al. (2013), } \\
\text { Xavier e Cunha } \\
\text { (2015), Mata } \\
\text { (2009), Farias J. } \\
\text { (2012), Costa R. } \\
\text { (2013) }\end{array}$ & $\begin{array}{l}\text { - Planta } \\
\text { inteira }\end{array}$ & $\begin{array}{l}\text { - Planta seca colocada em } \\
\text { locais diversos da casa para } \\
\text { afugentar insetos; } \\
\text { - Queima da planta seca ao } \\
\text { redor da casa para repelir } \\
\text { insetos; } \\
\text { - Pendurar galhos pela casa } \\
\text { para espantar insetos e } \\
\text { outros animais }\end{array}$ \\
\hline Mucuracaá & Petiveria alliacea $\mathrm{L}$. & Phytolaccaceae & Herbáceo & $\begin{array}{l}\text { Carvão, Curiaú, } \\
\text { Mazagão Velho, } \\
\text { Mazagão-estuário, } \\
\text { Flona }\end{array}$ & $\begin{array}{l}\text { Silva (2002, 2010), } \\
\text { Nascimento (2011), } \\
\text { Silva et al. (2013), } \\
\text { Oliveira et al. } \\
\text { (2013), Farias J. } \\
\text { (2012), Costa R. } \\
\text { (2013) }\end{array}$ & - Folhas & $\begin{array}{l}\text { - Queimar as folhas para } \\
\text { espantar os insetos e } \\
\text { outros bichos; } \\
\text { - Tintura, passar no corpo } \\
\text { para repelir insetos }\end{array}$ \\
\hline Pau de ângola & Piper divaricatum G. Mey. & Piperaceae & Arbustivo & Carvão, Curiaú, Flona & $\begin{array}{l}\text { Silva (2002, 2010), } \\
\text { Souto et al. (2011), } \\
\text { Pereira et al. } \\
\text { (2007), Costa R. } \\
\text { (2013) }\end{array}$ & - Folhas & $\begin{array}{l}\text { - Queima da planta para } \\
\text { fazer fumaça e espantar os } \\
\text { insetos; } \\
\text { - Colocar o material em } \\
\text { álcool e usar para passar no } \\
\text { corpo para espantar os } \\
\text { insetos e aliviar } \\
\text { desconforto de picadas }\end{array}$ \\
\hline $\begin{array}{l}\text { Pau mulateiro, pau } \\
\text { mulato }\end{array}$ & $\begin{array}{l}\text { Calycophyllum spruceanum } \\
\text { (Benth.) Hook.f. ex K.Schum. }\end{array}$ & Rubiaceae & Arbóreo & $\begin{array}{l}\text { Carvão, Matão do } \\
\text { Piaçacá }\end{array}$ & $\begin{array}{l}\text { Silva (2010), Melo } \\
\text { (2015) }\end{array}$ & $\begin{array}{l}\text { - Folhas e } \\
\text { cascas } \\
\text { - Cascas }\end{array}$ & $\begin{array}{l}\text { - A queima das folhas para } \\
\text { produzir fumaça e espantar } \\
\text { os insetos; } \\
\text { - A queima das cascas para } \\
\text { produzir fumaça e espantar } \\
\text { os insetos }\end{array}$ \\
\hline Pimenta de macaco & Piper aduncum L. & Piperaceae & Arbustivo & Curiaú & Souto et al. (2011) & $\begin{array}{l}-\quad \text { Planta } \\
\text { inteira }\end{array}$ & $\begin{array}{l}\text { - Queima da planta para } \\
\text { fazer fumaça e espantar os } \\
\text { insetos; } \\
\text { - Colocar o material em } \\
\text { álcool e usar para passar no } \\
\text { corpo para espantar os } \\
\text { insetos }\end{array}$ \\
\hline
\end{tabular}




\begin{tabular}{|c|c|c|c|c|c|c|c|}
\hline $\begin{array}{l}\text { Salva de marajó, } \\
\text { sarva }\end{array}$ & Hyptis crenata Pohl ex Benth. & Lamiaceae & Herbáceo & Macapá & Ramos (2014) & $\begin{array}{l}\text { - Planta } \\
\text { inteira }\end{array}$ & $\begin{array}{l}\text { - Fazer a queima da planta } \\
\text { para a fumaça afastar os } \\
\text { insetos; } \\
\text { - Colocar a planta em } \\
\text { pontos estratégicos da casa } \\
\text { para afastar os insetos, } \\
\text { traças e baratas; } \\
\text { - Colocar a planta em } \\
\text { garrafa com álcool e deixar } \\
\text { de molho, após usar } \\
\text { passando diretamente na } \\
\text { pelo para afastar os insetos }\end{array}$ \\
\hline Tabaco & Nicotiana tabacum L. & Solanaceae & Herbáceo & Flona & Costa R. (2013) & - Folhas & $\begin{array}{l}\text { - Colocar a folha em extrato } \\
\text { de álcool e passar na pele } \\
\text { para espantar insetos; } \\
\text { - Macerar as folhas e passar } \\
\text { na pele para repelir insetos; } \\
\text { - Macerar as folhas e passar } \\
\text { na pele para aliviar o } \\
\text { desconforto de picada de } \\
\text { insetos }\end{array}$ \\
\hline $\begin{array}{l}\text { Urucurizeiro, } \\
\text { urucuri }\end{array}$ & $\begin{array}{l}\text { Attalea phalerata Mart. ex } \\
\text { Spreng. }\end{array}$ & Arecaceae & Arbóreo & Mazagão & Dantas et al. (2014) & $\begin{array}{l}\text { - Bráctea } \\
\text { dos frutos }\end{array}$ & $\begin{array}{l}\text { - Fazer a queima das } \\
\text { brácteas para produzir } \\
\text { fumaça e espantar os } \\
\text { insetos }\end{array}$ \\
\hline
\end{tabular}

Fonte: Pesquisa de campo (2016). 
Com relação à forma de vida das espécies em questão, destacam-se as arbóreas (40\%), o herbáceo (32\%), o arbustivo (16\%) o sub-arbustivo (8\%) e o escandente (4\%). Araújo et al. (2018) encontrou como as principais formas de vida vegetal usadas como repelentes e/ou inseticidas, as espécies herbáceas e arbustivas (45,45\% cada) e as arbóreas (9,10\%). Villavicencio-Nieto et al. (2010) registraram as principais formas de vida vegetal as espécies arbustivas $(37,90 \%)$, herbáceas $(33,06 \%)$ e arbóreas (25\%).

De uma maneira geral, no preparo de algum extrato ou uso direto como repelente e/ou inseticida são usadas folhas, quando a espécie tem modo de vida arbóreo ou arbustivo e por vezes, quando a espécie é herbácea, é usada a planta inteira. Essas práticas quase sempre são extrativas e, com isso, se deve ter o cuidado de cultivo e manejo no sentido de manutenção dessas espécies.

\section{Conclusões}

Diversos estudos e pesquisas têm demonstrado a importância do conhecimento etnobotânico e etnofarmacológico para a demonstração da riqueza biológica e cultural da Amazônia e, em especial, do estado do Amapá, o que é de extrema importância, pois esses trabalhos trazem informações sobre a potencialidade existente da biodiversidade vegetal, bem como o grau e intensidade de uso tradicional de recursos florestais pela população, através de diversas fontes, como os trabalhos acadêmicos.

Os números apontados nesse trabalho são indicativos da evidente riqueza da diversidade vegetal sendo usada como repelente e/ou inseticida no estado Amapá, sendo um fator motivador para se ampliar e aprofundar pesquisas nas áreas de ciências agrárias, florestais, da saúde e farmacológicas.

Toda a fonte de informações científicas pode e deve servir de suporte para estudos apurados para o desenvolvimento de produtos naturais nas descobertas de novas substâncias bioativas, bem como na produção e aprimoramento de fármacos, no contexto da produção de inseticidas, repelentes e fitocosméticos, que estejam a disposição da população como tecnologia social, não patenteáveis.

\section{Agradecimentos}

O autor agradece à Coordenação de Aperfeiçoamento de Pessoal de Nível Superior (CAPES) pela concessão da bolsa de pós-doutorado, assim como ao Programa de Pós-Graduação em Ciências da Saúde da Universidade Federal do Amapá pela oportunidade.

\section{Referências}

ACIOLE, S. D. G. Avaliação da atividade inseticida dos óleos essenciais das plantas amazônicas Annonaceae, Boraginaceae e da Mata Atlântica Myrtaceae como alternativa de controle às larvas de Aedes aegypti (Linnaeus, 1762) (Diptera: Culicidae). 2009. 72 f. Dissertação (Mestrado em Biologia Humana e Ambiente) - Departamento de Biologia Animal, Faculdade de Ciências, Universidade de Lisboa, Lisboa, 2009.

ALVES, D. L.; SILVA, C. R. Fitohormônios: abordagem natural da terapia hormonal. São Paulo: Atheneu, 2002.105 p.

APG IV. An update of the Angiosperm Phylogeny Group classification for the orders and families of flowering plants: APG IV. Botanical Journal of the Linnean Society, v. 181, p. 1-20, 2016.

ARAÚJO, E. A. S. O. et al. Levantamento de plantas fitossanitárias utilizadas no manejo de pragas agrícolas. Revista Brasileira de Agroecologia, v. 13, n. 4, p. 163-174, 2018.

AZEVEDO, T. S. et al. Perfil epidemiológico da dengue no município de Rio Claro no período de 19962010. Hygeia, Revista Brasileira de Geografia Médica e da Saúde, v. 7, n. 12, p. 19-30, 2011.

BARRETO, C. F. Aedes aegypti - resistência aos inseticidas químicos e as novas alternativas de controle. Revista Eletrônica Fac. Montes Belos, v. 1, p. 62-73, 2005.

BEZERRA, D. P. et al. Piplartine induces inhibition of leukemia cell proliferation triggering both apoptosis and necrosis pathways. Toxicology in vitro, v. 21, p. 1-8, 2007.

BRAGA, I. A.; VALLE, D. Aedes aegypti: inseticidas, mecanismos de ação e resistência. Epidemiologia e Serviços de Saúde, v. 16, n. 4, p. 279-293, 2007. 
CASTRO, M. J. P. Potencial inseticida de extratos de Piper tuberculatum Jacq. (Piperaceae) sobre a dase larval de Spodoptera frugiperda (J. E. Smith). 2007. 56 f. Dissertação (Mestrado em agronomia) - Universidade Federal do Piauí, Terezinha, 2007.

CASTRO, M. J. P. et al. Potencial de extratos de frutos secos e desidratados de Piper tuberculatum Jacq. (Piperaceae) no desenvolvimento da lagarta-do-cartucho do milho. Magistra. Cruz das Almas-BA, v. 22, n. 2, p. 8895, abr./jun., 2010.

CONSOLI, R. A. G. B. Principais mosquitos de importância sanitária no Brasil. Rio de Janeiro: Fiocruz, 1994.228 p. COSTA, R. A. A identidade e o conhecimento etnobotânico dos moradores da Floresta Nacional do Amapá. 2013. 104 f. Dissertação (Mestrado em Biodiversidade Tropical) - Universidade Federal do Amapá, Macapá, 2013.

COSTA, E. V. M. Estudo etnobotânico sobre plantas utilizadas como antimaláricas no Estado do Amapá e avaliação da atividade antimalárica e toxicidade aguda de Amasonia campestris (Aubl.). 2013. 142 f. Tese (Doutorado em Biodiversidade Tropical) - Universidade Federal do Amapá, Macapá, 2013.

CRIVELENTI, L. Z. et al. Toxicidade do inseticida organofosforado Abate ${ }^{\circledR}$ em alevinos de Poecilia reticulata. J. Braz, Soc. Ecotoxicol., v. 6, p. 65-68, 2011.

DANTAS, A. R. et al. Produção de frutos de urucurizeiros, Attalea excelsa Mart. (Arecaceae), em floresta de várzea no estuário do rio Amazonas. Biota Amazônica, Macapá, v. 4, n. 4, p. 108-114, 2014.

ESTRELA, J. L. V. et al. Toxicidade de amidas análogas à piperina a larvas de Ascia monuste orseis Godart (Lepidoptera: Pieridae) e Spodoptera frugiperda (J. E. Smith) (Lepidoptera: Noctuidae). Neotropical Entomology, v. 32, p. 343-346, 2003.

ESTRELA, J. L. V. et al. Toxicidade de óleos essenciais de Piper aduncum e Piper hispidinervum em Sitophilus zeamais. Pesq. agropec. bras., Brasília, v.41, n.2, p.217-222, fev. 2006.

FARIAS, A. M. Bioatividade do óleo essencial de Piper tuberculatum Jacq. Sobre a lagarta-do-cartucho do milho Spodoptera frugiperda (J. E. Smith 1797) (Lepidoptera: Noctuidae). 2012. 61 f. Dissertação (Mestrado em Agronomia) - Centro de Ciências Agrárias, Universidade Federal do Piauí, Terezina, 2012.

FARIAS, J. E. S. Manejo de açaizais, riqueza florística e uso tradicional de espécies de várzeas do Estuário Amazônico. 2012. 102 f. Dissertação (Mestrado em Biodiversidade Tropical) - Universidade Federal do Amapá, Macapá, 2012.

FARIAS, J. C. et al. Plantas inseticidas e repelentes utilizadas em uma comunidade rural no Nordeste brasileiro. Espacios, v. 37, n. 22, p. 6-16, 2016.

FORZZA, R. C. et al. Flora do Brasil 2020 em construção. Jardim Botânico do Rio de Janeiro. Disponível em: <http://floradobrasil.jbri.gov.br/>. Acesso em: 10 jun. 2018

GALLO, D. et al. Entomologia agrícola. Piracicaba: Fealq, 2002. 920 p.

GARCEZ, W. S. et al. Substâncias de origem vegetal com atividade larvicida contra Aedes aegypti. Revista Virtual de Química, v. 5, n. 3, p. 363-393, 2013.

GARCIA, O. R. Aedes aegypti, vírus dengue, chinkugunia, zika y el cambio climático. Máxima alerta médica y oficial. Revista Eletrônica de Veterinária, v. 15, n. 10, p. 1-10, 2014.

GONÇALVES, A. P.; LIMA, R. A. Identificação das classes de metabólitos secundários do extrato etanólico de Piper tuberculatum Jacq. South American Journal of Basic Edication, Tachnical and Technological, v. 3, n. 2, p. 100-109, 2016.

GUIMARÃES, E. F.; MONTEIRO, D. Piperaceae na Reserva Biológica de Poço das Antas, Silva Jardim, Rio de Janeiro, Brasil, Rodriguésia, v. 57, n. 3, p. 567-587, 2006.

GUISSONI, A. C. et al. Atividade larvicida de Annacardium occidentale como alternativa ao controle de Aedes aegypti e sua toxicidade em Rattus norvergicus. Rev. Bras. PI. Med., v. 15, p. 363-367, 2013.

HOLETZ, F. B. et al. Screening of some plants used in the Brazilian folk medicine for the treatment of infeccious diseases. Memórias do Instituto Oswaldo Cruz, v. 97, p. 1027-1031, 2002.

HORTA, M. A. P. et al. Resistance of Aedes aegypti (L.) (Diptera: Culicidae) to temephos in Brazil: a revision and new data for Minas Gerais State. Bio Assay, v. 6, p. 1-6, 2011.

KATO, M. J.; FURLAN, M. Chemistry and evoluciono of the Piperaceae. Pure and Applied Chemistry, v. 79, n. 4, p. 529-538, 2007.

KWEKA, J. et al. Ethnobotanical study of some of mosquito plants in north-eastern Tanzania. Malaria Journal, v. 7, n. 152, p. 1-9, 2008.

LAGO, J. H. et al. Benzoic acid derivatives from Piper species and their fungitoxic activity against Cladosporium cladosporioides and C. sphaerospermum. Journal of Natural Products. v. 67, p. 1783-1788, 2004.

MATA, N. D. S. Participação da mulher waiãpi no uso tradicional de plantas medicinais. 2009. $141 \mathrm{f}$. Dissertação (Mestrado em Desenvolvimento Regional) - Universidade Federal do Amapá, Macapá, 2009.

MARANGONI, C. et al. Utilização de óleos essenciais e extratos de plantas no controle de insetos. Rev. Ciênc. Amb., v. 6, p. 95-112, 2012.

McNEILL, J. et al. Código Internacional de Nomenclatura Botânica (Código de Viena). São Carlos-SP: Rima Editora, 2007. $181 \mathrm{p}$. 
MINAYO, M. C. S. O desafio do conhecimento: pesquisa qualitativa em saúde. 14. ed. São Paulo: Hucitec, 2014. $407 \mathrm{p}$.

MELO, N. C. Avaliação da atividade protetora solar in vitro das espécies pau-mulato (Calycophyllum spruceanum (Benth.) Hook. f. ex K. Schum) e ipê-amarelo (Tabebuia aurea (Silva Manso) Benth. \& Hook. f. ex S. Moore). 2015. 90 f. Dissertação (Mestrado em Ciências da Saúde) - Universidade Federal do Amapá, Macapá, 2015.

MORAIS, L. A. S. de. Controle fitossanitário em assentamento de base agroecológica: um resgate do conhecimento tradicional. Revista Brasileira de Agroecologia, Cruz Alta, v. 6, n. 1, p. 57-66, 2011.

MORAIS, L. A. S.; MARINHO-PRADO, J. S. Plantas com atividade inseticida. In: HALFELD-VIEIRA, B. A. et al. (Ed.). Defensivos agrícolas naturais: uso e perspectivas. Brasília-DF: Embrapa, 2016 . 542-593.

MORITA, M. et al. Molecular cloning and functional expression of triterpene synthases from pea (Pisum sativum). European Journal of Biochemistry, v. 267, p. 3453-3460, 2000.

NASCIMENTO, M. E.; POTIGUARA, C.R.V. Aspectos anatômicos dos órgãos vegetativos de Piper hispidinervium C. DC. (Piperaceae) e suas estruturas secretoras. Boletim do Museu Paraense Emílio Goeldi; Série Botânica, v. 15, p. 39-104, 1999.

NASCIMENTO, E. S. Levantamento dos conhecimentos etnobotânicos de comunidades ribeirinhos do estuário amapaense. 2011. 86 f. Trabalho de Conclusão de Curso (Graduação em Engenharia Florestal) - Universidade do Estado do Amapá, Macapá, 2011.

OLIVEIRA, D. S. B. et al. Phytochemical study, microbiological and cytotoxicity activity in Artemia salina Leach, aerial parts of Petiveria alliacea L. Phytolaccaceae. Biota Amazônica, Macapá, v. 3, n. 3, p. 76-82, 2013.

PEREIRA, L. A. et al. Plantas medicinais de uma comunidade quilombola na Amazônia Oriental: aspectos utilitários de espécies das famílias Piperaceae e Solanaceae. Rev. Bras. de Agroecologia, v. 2, n. 2, p. 1385-1388. out. 2007.

PESSINI, G. L. et al. Análise farmacognóstica de Piper regnelli var. palescens (C.DC.) Yunck. aspectos botânicos e enfoque físico-químico preliminar. Acta Farmacêutica Bonaerense, v. 22, p. 209-216, 2003.

RAMOS, R. S. Estudo fitoquímico da atividade microbiológica de citoxicidade e larvicida dos óleos essenciais de espécies da família Lamiacea (LAMIALES). 2014. 86 f. Dissertação (Mestrado em Ciências Farmacêuticas) Universidade Federal do Amapá, Macapá, 2014.

RAMOS, R. S. et al. Estudo físico-químico e avaliação do potencial larvicida do extrato etanólico das cascas do caule de Licania macrophylla Benth. Biota Amazônica, Macapá, v. 5, n. 1, p. 74-78, 2015.

REY, J. R. et al. Resurgencia del dengue em América: pautas, processos y prospectos. Interciencia, v. 35, p. 800-806, 2010.

RODRIGUES, J. C. Plantio de uma horta na Escola Estadual Antônio Messias: valorização de Ciências a partir do cultivo de plantas medicinais. 2008. 39 f. Trabalho de Conclusão de Curso (Graduação em Licenciatura Plena em Biologia) - Universidade Federal do Amapá, 2008.

ROEL, A. R. Utilização de plantas com propriedades inseticidas: uma contribuição para o Desenvolvimento Rural Sustentável. Revista Internacional de Desenvolvimento Local, v.1, n. 2, p. 43-50, 2001.

ROEL, A. R. et al. Atividade tóxica de extratos orgânicos de Trichilia pallida Swartz (Meliaceae) sobre Spodoptera frugiperda (J. E. Smith). An. Soc. Entomol. Bras., v. 29, p.799-808, 2000.

SANTOS, A. G. et al. Fitocosméticos. In: SOUZA, G. H. B.; MELLO, J. C. P. (org.). Farmacognosia: coletânea científica. Ouro Preto: UFOP, 2012, p. 19-68.

SANTOS, M. A. C. Levantamento de espécies vegetais úteis das áreas Sucurijú e Região dos Lagos, no Amapá. In: COSTA NETO, S. V. (org.). Inventário biológico das áreas do Sucurijú e Região dos Lagos, no Amapá: Relatório final PROBIO. Macapá: IEPA, 2006. P. 80-106.

SANTOS, M. N. et al. Saberes tradicionais em uma unidade de conservação localizada em ambiente periurbano de várzea: etnobiologia da andirobeira (Carapa guianensis Aublet). Boletim do Museu Paraense Emílio Goeldi. Ciências Humanas, v. 9, n. 1, p. 93-108, jan.-abr. 2014.

SCHULTES, R. E.; RAFFAUF, R. F. The healing forest: medicinal and toxic plants of the northwest Amazonia. Oregon, Dioscorides Press, 1990. 484 p.

SILVA, E. M. J.; MACHADO, S. R. Estrutura e desenvolvimento dos tricomas secretores em folhas de Piper regnellii C.DC. (Piperaceae). Revista Brasileira de Botânica, n. 22, p. 117-124, 1999.

SILVA, R. B. L. e. A etnobotânica de plantas medicinais da comunidade quilombola de Curiaú, Macapá-AP, Brasil. 2002. 170 f. Dissertação (Mestrado em Agronomia) - Departamento de Biologia Vegetal, Faculdade de Ciências Agrárias do Pará, Belém, 2002.

SILVA, R. B. L. e. Diversidade, uso e manejo de quintais agroflorestais no Distrito do Carvão, Mazagão-AP, Brasil, 2010. 284 f. Tese (Doutorado em Desenvolvimento Sustentável do Trópico Úmido) - Universidade Federal do Pará/Núcleo de Altos Estudos Amazônicos, Belém, 2010.

SILVA, R. B. L. et al. Caracterização agroecológica e socioeconômica dos moradores da comunidade quilombola do Curiaú, Macapá-AP, Brasil. Biota Amazônia, Macapá, v. 3, n. 3, p. 113-138, 2013.

SIMÕES, C. M. O. et al. Farmacognosia: da planta ao medicamento. 6. ed. UFRGS/UFSC. Porto Alegre/Florianópolis, Brasil, 2010. 1104 p. 
SODERLUND, D. M. et al. Mechanisms of pyrethroid neurotoxicity: implications for cumulative risk assessment. Toxicology, v. 171, p. 3-59, 2002.

SOUTO, R. N. P. S. et al. Estudos preliminares da atividade inseticida de óleos essenciais de espécies de Piper linneus (piperaceae) em operárias de Solenopis saevissima f Smith (Hymenoptera: formicidae ), em laboratório. Biota Amazônica. Macapá, v. 1, n. 1, p. 42-48, 2011.

SOUZA, L. J. (org.). Dengue, zika e chikungunya: diagnóstico, tratamento e prevenção. 1. ed. Rio de Janeiro: Rubio, 2016. 204 p.

TAVIL, P. L. Aspectos críticos do controle da febre amarela no Brasil. Revista de Saúde Pública, v. 44, n. 3, p. 555$558,2010$.

THE PLANT LIST. A working list of all plant species. Version 1.1. 2013. Disponível em: <http://www.theplantlist.org/>. Acesso em: 1 mai. 2018.

TROPICOS.ORG. Missouri Botanical Garden. Disponível em: <http://www.tropicos.org>. Acesso em: 3 jun. 2018.

VASCONCELOS, P. F. C. Doença pelo vírus zika: um novo problema emergente nas Américas. Rev Pan-Amaz Saude, v. 6, n. 2, p. 9-10, 2015.

VIEGAS JUNIOR, C. Terpenos com atividade inseticida: uma alternativa para o controle químico de insetos. Quim. Nova, v. 26, p. 390-400, 2003.

VILLAVICENCIO-NIETO, M. À. et al. Plantas tradicionalmente usadas como plaguicidas em el estado de Hidalgo, México. Polibotánica, n. 30, p. 193-238, 2010.

XAVIER, W. K. S.; CUNHA, E. D. S. Comercialização de produtos naturais medicinais oriundos do Estado do Amapá. Biota Amazônica, Macapá, v. 5, n. 2, p. 23-25, 2015.

YUNCKER, T. G. The Piperaceae of Brazil I: Piper - Group I, II, III, IV. Hoehnea, v. 2, p. 19-366, 1972.

YUNCKER, T. G. The Piperaceae of Brazil II: Piper - Group V; Ottonia; Pothomorphe; Sarcorhachis. Hoehnea, v. 3, p. 121-144, 1973.

YUNCKER, T. G. The Piperaceae of Brazil III: Peperomia; taxa of uncertain status. Hoehnea, v. 4, p. 71-413, 1974. 